\title{
Descriptive study to assess the knowledge on risk factors of Coronary Artery Disease (CAD)
}

\section{Betcy George $^{1 *}$, Christina Johnson Chittinapilly², Christy Annie William², Christy Paul'2, Cincy Jose ${ }^{2}$, Deepa Anna John², Dinet George ${ }^{2}$, Divya Divakaran², Dona Titus², Gitty George², Hanna Baby², Jeciya Paulose ${ }^{2}$ and Jilu Thomas ${ }^{2}$ \\ ${ }^{1}$ Assistant Professor, MOSC College of Nursing, Kolenchery, PhD Scholar, Sri Ramachandra Institute of Higher Education and Research, Chennai, India \\ ${ }^{2} 3$ rd Year BSc Nursing Students, MOSC College of Nursing, Kolenchery, Sri Ramachandra Institute of Higher Education and Research, Chennai, India}

\section{Summary}

$C A D$ is the most common type of CVD which is characterized by deposits of lipids within the intima of the coronary artery. CAD is the leading cause of mortality and morbidity in many countries worldwide.

The investigators adopted a quantitative approach to assess the knowledge on risk factors of CAD among patients in selected OPDs of M.O.S.C Medical College Hospital, Kolenchery. A descriptive design with non-probability convenience sampling technique was used. 120 clients who have given consent and shown willingness to participate were enrolled in the study. Data was collected by using demographic proforma, and structured knowledge questionnaire.

The data was analyzed using descriptive and inferential statistics. The collected data was organized tabulated and analyzed by descriptive [mean, median, mode and standard deviation] and inferential statistics [chi-square test].

The data revealed that the level of knowledge on risk factors of cad among subjects attending selected OPDs, out of 120 samples $30(25 \%)$ have good knowledge, $85(71 \%)$ have average knowledge and only $5(4 \%)$ have poor knowledge.

There was significant association between knowledge level and education whereas there was no significant association between age, sex, religion, income, marital status, occupation and food habit.

\section{More Information}

*Address for Correspondence: Betcy George, Assistant Professor, MOSC College of Nursing, Kolenchery, PhD Scholar, Sri Ramachandra Institute of Higher Education and Research, Chennai, India, Email: betccy@gmail.com

Submitted: September 16, 2021 Approved: September 28, 2021 Published: September 30, 2021

How to cite this article: George B, Chittinapilly CJ, William CA, Paul C, Jose C, et al. Descriptive study to assess the knowledge on risk factors of Coronary Artery Disease (CAD). Clin J Nurs Care Pract. 2021; 5: 051-054. DOI: 10.29328/journal.cjncp.1001037

Copyright License: ( 2021 George B, et al. This is an open access article distributed under the Creative Commons Attribution License, which permits unrestricted use, distribution, and reproduction in any medium, provided the original work is properly cited.

D) Check for updates

OPEN ACCESS

\section{Introduction}

CAD is the most common type of CVD which is characterized by deposits of lipids within the intima of the coronary artery. More than 17 million people die annually from CVD. Many of these people have been exposed to unhealthy behaviours, including tobacco use, eating foods containing too much salt and inadequate physical activity. India is facing an epidemiological transmission for prevalence of CAD. According to WHO, an estimated 1.28 billion adults aged 30-79 years worldwide have CAD, most (two-thirds) living in low- and middle-income countries [1]. Epidemiologists estimate that by 2025, nearly 1.56 billion adults will be hypertensive; given an additional $60 \%$ surge in comparison to the hypertensive population in the year 2000 [2].

The major risk factors responsible for the CAD epidemic in India are age, gender, ethnicity, family history, genetics, elevated serum lipids, elevated blood pressure, obesity, Diabetes mellitus, metabolic syndrome and elevated homocysteine levels [3].

Modern world continue to be ill- equipped to handle the burden of occurrence of CVD and this coupled with poor literacy rates and lack of awareness of disease symptoms result in worse disease outcomes. This is reflected in the rising rates of hospital admissions and mortality from CVD 
at an early age [4]. Therefore an urgent need to understand baseline knowledge levels of CVD. So we have planned to assess the knowledge regarding risk factors of CAD.

\section{Purpose of the study}

CAD is becoming a major global health problem. India is facing an epidemiological transition for prevalence of CAD. In Kerala, the prevalence of life style diseases like diabetes, heart disease, high blood pressure and obesity is high and it results in very high mortality and morbidity from malignant heart disease. $14 \%$ of all deaths in Kerala are caused by CAD. Approximately $60 \%$ of CAD deaths in men and $40 \%$ of CAD deaths in women occur before the age of 65 years that is at very young age as CAD in Kerala is premature and malignant [5].

CAD arises due to non-modifiable risk factors which include age, gender, ethnicity, family history and genetics. Modifiable risk factors include elevated serum lipids, elevated blood pressure, obesity, diabetes mellitus, metabolic syndrome and elevated homocystein levels.

A cross sectional survey was conducted in Bangladesh to knowledge, attitudes and practices among 222 patients with coronary artery disease using a 40 point KAP survey. The mean KAP score was $21.45 \pm 5.83$ with a total possible score being $40.5 .86 \%$ of the sample could suggested a high level of proficiency. Men had more knowledge $(\mathrm{t}(1.962)=1.334$, $p=0.051$ ), but women demonstrated more health-seeking behaviors with stronger statistical significance $(\mathrm{t}(-2.135)=$ $-0.407, p=0.034)$. The study concluded selective lapses in CAD knowledge, attitude, and practice among Bangladeshi patients [6].

Above mentioned statistics gave information regarding the risk factors of CAD. So it is evident that by changing the life style of people, their believes and practices one can lead a better life. In our institution also many patients are coming with risk factors of CAD. So it is necessary to assess the knowledge of people with risk factors of CAD. In view of all the aspect the investigators decided to conduct the study among middle aged male and female patients (18-65 years).

\section{Statement of the problem}

"A study to assess the knowledge regarding risk factors of Coronary Artery Disease among patients attending OPDs of MOSC Hospital, Kolenchery."

\section{Objectives}

1. To assess the knowledge regarding risk factors of CAD

2. To find out the association between knowledge level and selected demographic variables

Hypothesis [Level of significance at 0.05 level]

$\mathrm{H}_{1}$ - There is significant association between knowledge level and selected demographic variables among patients attending OPDs of MOSC Hospital.

\section{Materials and methods}

- Setting of the study: Selected OPDs of MOSC Medical College Hospital, Kolenchery

- Research approach: Quantitative approach

- Research design: The design used in this study was descriptive design

- Sample size

Based on the results of pilot study the sample size was calculated using my sample size calculation software developed by department of Biostatistics. The sampling technique used was convenience sampling technique. The following formula was used to calculate sample size.

$$
\mathrm{n}=\frac{\mathrm{Z}_{1-\alpha / 2}^{2} \sigma^{2}}{(\mu \mathrm{d})^{2}}
$$

Where,

$\sigma=$ Anticipated standard deviation (7.02)

$\mathrm{Z}_{1-\alpha / 2}=1.96($ at $5 \% \alpha)$

$\mu=$ Anticipated mean (87.9)

$\mathrm{d}=$ Precision $(2 \%)$

The required sample size at precision $2 \%$ was 61.3 subjects. 120 subjects were selected for the study.

- Sample: The sample size was 120 patients attending selected OPDs

- Sampling Technique: Convenient sampling technique

- Inclusion criteria: Clients who are able to read and write Malayalam and who were between age of 1865 years attending selected OPDs of MOSC Medical College Hospital, Kolenchery

- Data collection instruments:

Tool 1: Demographic proforma.

It consist of 8 questions for collecting demographic data such as age, sex, religion, educational status, occupation, income, marital status and type of diet.

Tool 2: Structured knowledge questionnaire.

To assess the knowledge on risk factors of CAD. Items on questionnaire covered various aspects of CAD including anatomy, definition, etiology, risk factors, clinical features, diagnostic evaluation, management and prevention of CAD.

Scoring: Structured multiple choice questionnaire 
consisted of 20 items. A score of $0 \%-35 \%$ indicated poor knowledge $36 \%$ - 70\% indicated average knowledge and $71 \%-100 \%$ indicated good knowledge.

\section{Content validity}

To ensure the content validity, the tool was submitted to three experts in the field of Cardiology, Paediatric and Medical Surgical Nursing. They were requested to judge the items for its relevance, appropriateness and the degree of agreement for the study. Content validity index was calculated. Items with a content validity index more than $90 \%$ were included in the tool.

Reliability of the tool: Reliability of the questionnaire was assessed by Split half method and the tool was found to be highly reliable $(r=0.81)$.

\section{Ethical clearance}

Initially the researcher obtained ethical clearance from institutional ethics committee and permission from administrative authorities of MOSC Medical College Hospital, Kolenchery. Researchers introduced themselves and the purpose and details of the study were explained to them. An informed consent was obtained from the subjects after assuring anonymity and confidentiality.

\section{Data collection procedure}

About 300 patients were attending selected OPDs (Cardiac, Neuro, General medicine) daily. The investigators met the subject and explained about the present study. Patient information sheet and informed consent form were given to them. 120 clients who have given consent and shown willingness to participate were enrolled in the study.

\section{Results}

Data were analysed by descriptive and inferential statistics using Microsoft excel and R software.

Section 1: Data on level of knowledge on risk factors of CAD among patients attending selected OPDs (Table 1).

The Figure 1 shows the level of knowledge on risk factors of CAD among subjects attending selected OPDs, out of 120 samples 30 (25\%) have good knowledge, 85 (71\%) have average knowledge and only 5 (4\%) have poor knowledge.

The Table 2 shows that the median of the text is 13 and Interquartile range is $(11,14.75)$.

Section 2: For doing Chi-Square test the knowledge level was categorized in to average (0-14) and good (15-20) $n=120$.

Table 3 shows that there was significant association between knowledge level and education whereas there was no significant association between age, sex, religion, income, marital status, occupation and food habit.

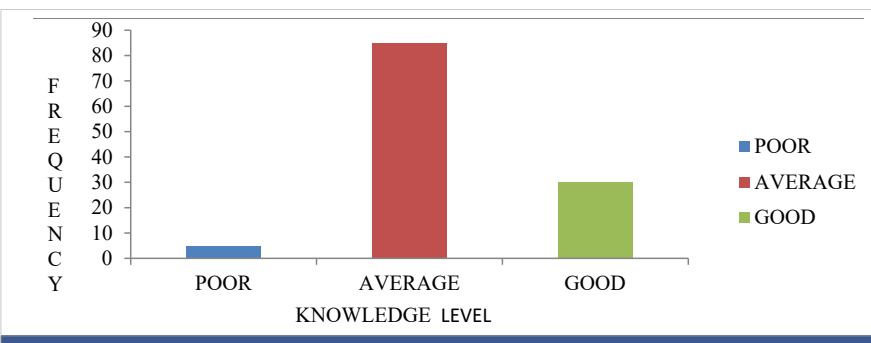

Figure 1: Frequency distribution of subjects' knowledge level on risk factors of CAD.

\begin{tabular}{|c|c|c|}
\hline \multicolumn{2}{|c|}{ Table 1: Frequency and percentage distribution of level of knowledge $n=120}$. \\
\hline Level of knowledge & Frequency & Percentage (\%) \\
\hline Poor knowledge (0-7) & 5 & 4 \\
\hline Average knowledge (8-14) & 85 & 71 \\
\hline Good knowledge (15-20) & 30 & 25 \\
\hline
\end{tabular}

\begin{tabular}{|c|c|}
\hline Table 2: Median and Interquartile range of knowledge level. \\
\hline Median & 13 \\
\hline $\mathrm{Q}_{1}, \mathrm{Q}_{3}$ & $(11,14.75)$ \\
\hline
\end{tabular}

Table 3: Frequency, percentage and chi-square distribution of knowledge level on risk factors for CAD among patients attending selected OPDs.

\begin{tabular}{|c|c|c|c|c|c|}
\hline \multirow{2}{*}{\multicolumn{2}{|c|}{ Demographic variables }} & \multicolumn{2}{|c|}{ Knowledge } & \multirow{2}{*}{ Chi-square } & \multirow{2}{*}{$p$ - value } \\
\hline & & \multirow{2}{*}{$\begin{array}{c}\text { Average } \\
41\end{array}$} & \multirow{2}{*}{$\begin{array}{c}\text { Good } \\
15\end{array}$} & & \\
\hline \multirow{2}{*}{ Age } & $20-45$ & & & \multirow{2}{*}{0.17} & \multirow{2}{*}{0.67} \\
\hline & $46-65$ & 49 & 15 & & \\
\hline \multirow{2}{*}{ Sex } & Female & 45 & 18 & \multirow{2}{*}{0.902} & \multirow{2}{*}{0.342} \\
\hline & Male & 45 & 12 & & \\
\hline \multirow{4}{*}{ Education } & Illiterate & 13 & 1 & & \\
\hline & High school/PDC & 50 & 12 & \multirow{3}{*}{ - } & \multirow{3}{*}{$<0.001^{*}$} \\
\hline & Degree & 11 & 15 & & \\
\hline & Post graduate & 16 & 2 & & \\
\hline \multirow{4}{*}{ Religion } & Hindu & 38 & 11 & \multirow{4}{*}{2.63} & \multirow{4}{*}{0.453} \\
\hline & Christian & 36 & 16 & & \\
\hline & Islam & 12 & 3 & & \\
\hline & Others & 4 & 0 & & \\
\hline \multirow{4}{*}{ Income } & Below 5,000 & 38 & 8 & \multirow{4}{*}{2.49} & \multirow{4}{*}{0.478} \\
\hline & $5,000-10,000$ & 21 & 10 & & \\
\hline & $10,000-15,000$ & 18 & 7 & & \\
\hline & Above 15,000 & 13 & 5 & & \\
\hline \multirow{4}{*}{$\begin{array}{l}\text { Marital } \\
\text { Status }\end{array}$} & Married & 73 & 27 & \multirow{4}{*}{1.74} & \multirow{4}{*}{0.393} \\
\hline & Single & 12 & 2 & & \\
\hline & Widow & 1 & 1 & & \\
\hline & Widower & 4 & 0 & & \\
\hline \multirow[t]{4}{*}{ Occupation } & Daily labour & 29 & 3 & \multirow{4}{*}{6.38} & \multirow{4}{*}{0.094} \\
\hline & Skilled professional & 29 & 15 & & \\
\hline & Unskilled professional & 7 & 2 & & \\
\hline & Unemployed & 25 & 10 & & \\
\hline \multirow{2}{*}{$\begin{array}{l}\text { Food } \\
\text { Habits }\end{array}$} & Vegetarian & 18 & 3 & \multirow{2}{*}{5.18} & \multirow{2}{*}{0.144} \\
\hline & Mixed & 71 & 28 & & \\
\hline
\end{tabular}

\section{Discussion}

The subject's existing knowledge regarding risk factors of CAD was found to be average among the majority $71 \%$. A minority of them have good knowledge $25 \%$, and $4 \%$ is having poor knowledge. The study findings are in agreement with survey conducted in UK to assess the knowledge on risk factors of CAD in a sample of 5000 adults aged between 25-55 years. The results showed that, only $45 \%$ of subject correctly identified that CAD was the leading cause of death in their 
country. The study also identified that there is a significant gap in the knowledge about the risk factors of CAD.

\section{Conclusion}

In this study, majority of subjects in this study have average knowledge about the risk factors of CAD and the statistical analysis reveals that there was significant association between knowledge level and education. This study helps to assess the knowledge of clients regarding risk factors of CVD and to identify demographic variables associated knowledge is an important pre-requisite for implementing both primary as well as secondary preventive strategies of CVD.

\section{Acknowledgement}

Here we extend our sincere thanks to all the patients who participated in the study.

\section{References}

1. World Health Organization. Ageing and health. 2021. https://www. who.int/news-room/fact-sheets/detail/ageing-and-health

2. Chockalingam A, Campbell NR, Fodor JG. Worldwide epidemic of hypertension. Can J Cardiol. 2006; 22: 553-555.

PubMed: https://pubmed.ncbi.nIm.nih.gov/16755308/

3. Gupta S, Ramesh Gudapati KG, Bhise M. Emerging risk factors for cardiovascular diseases: Indian context. Indian J Endocrinol Metabol. 2013; 17: 806-814.

PubMed: https://pubmed.ncbi.nlm.nih.gov/24083161/

4. Choudhary M, Sharma K, Sodhi JK. Knowledge regarding preventive measures of coronary artery disease among patient attending out patient departments of selected hospital of Ludhiana city. Int J Healthcare Sci. 2014; 2: 60-63.

5. Reni M. Age (years). Int J Sci Res. 15: 01.

6. Mirza A, Aslam S, Perrin K, Curtis T, Stenback J, et al. Knowledge, attitudes and practices among patients with coronary artery disease in Dhaka, Bangladesh. Int J Commun Med Public Health. 2016; 3 : 2740-2748. 